\title{
Exploration on the training mode of application-oriented talents majoring in optoelectronic information
}

Hao Lv, Aimei Liu, Shengyi Zhang, Yongjun Xiao

Hao Lv, Aimei Liu II, Shengyi Zhang III, Yongjun Xiao IV, "Exploration on the training mode of application-oriented talents majoring in optoelectronic information," Proc. SPIE 10452, 14th Conference on Education and Training in Optics and Photonics: ETOP 2017, 104524l (16 August 2017); doi: $10.1117 / 12.2267930$

Event: 14th Conference on Education and Training in Optics and Photonics, ETOP 2017, 2017, Hangzhou, China 


\title{
Exploration on the Training Mode of Application-oriented Talents Majoring in Optoelectronic Information
}

\author{
Hao Lv*, Aimei Liu, Shengyi Zhang and Yongjun Xiao \\ The Key Laboratory of electric light source and lighting, School of Physics and Electronic \\ information engineering, Hubei Engineering University, Xiaogan 432000, P.R.China
}

\begin{abstract}
The optoelectronic information major is a strong theoretical and practical specialty. In view of the problems existing in the application-oriented talents training in the optoelectronic information specialty. Five aspects of the talent cultivation plan, the teaching staff, the teaching content, the practical teaching and the scientific research on the training mode of application-oriented talents majoring in optoelectronic information are putted forward. It is beneficial to the specialty construction of optoelectronic information industry which become close to the development of enterprises, and the depth of the integration of school and enterprise service regional economic optoelectronic information high-end skilled personnel base.
\end{abstract}

Keywords: training mode, application-oriented talents, optoelectronic information, majoring

\section{INTRODUCTION}

The development of information science and technology has a significant impact on human progress and social development. Information technology and industry have developed rapidly on a global scale and become a key factor for economic growth and social development of all countries in the world ${ }^{1}$. In the 21 st century, the development of information science and technology is still the leading force of sustained economic growth. The development of information industry is the key to promote new industrialization. Developed countries and emerging developing countries are very concerned about their information industry ${ }^{2-4}$. The National Medium- and Long-Term Education Reform and Development Plan ${ }^{5-6}$ (2010-2020) clearly states: "continuously optimize the structure of higher education, optimize disciplinary specialties, types, and hierarchical structures, and promote interdisciplinary and interdisciplinary integration, with an emphasis on applied, Skill-based personnel training scale." This is a strategic plan for personnel training in higher education under the background of economic transition. It is also the first time that the training of applied talents has been written into the official document at the national level. Application of talent is mainly in a certain theoretical norms, engaged in non-academic research work, its task is to abstract the theoretical symbols into specific operational concept or product configuration, the knowledge applied to practice. In other words, the application of talent is good at theoretical research and academic talents and practical skills of skilled personnel corresponding to both the theoretical basis and professionalism enough, but also the theory of practical knowledge will be applied to the actual talent.

Electronic information technology is an important field of information industry development, requires a large number of professionals, optical photoelectric information professional commitment to China's electronic information industry personnel training. With the development of electronics, communication, information and optoelectronic technologies, the opt-electronic information industry is based on mathematics, physics and information theory ${ }^{7-8}$. It is based on electronics, photon, information related components and electronic engineering, communication system and information network as the research object, from the component to the system, from the network to the service. The basic theory is complete, professional connotation is rich, the application field is extensive, the development is extremely rapid, promote the development of the information industry and upgrade the traditional industry one of the basis of professional. However, due to the influence of various factors, the related major of optoelectronic information-related major is usually attached importance to theoretical teaching while neglecting the influence of a series of factors such as practical teaching, practical teaching and unreasonable curriculum system. Students in professional knowledge and engineering practice

*kuerlvhao@hotmail.com

14th Conference on Education and Training in Optics and Photonics: ETOP 2017, edited by Xu Liu,

Xi-Cheng Zhang, Proc. of SPIE Vol. 10452, 104524I · @ 2017 ICO, IEEE, OSA, SPIE

CCC code: $0277-786 X / 17 / \$ 18 \cdot$ doi: $10.1117 / 12.2267930$ 
ability there is a big lack of schools cannot cultivate a large number of social and business needs of the application of talent ${ }^{9-10}$. Therefore, in order to meet the needs of local economic construction and social development, strengthen practice teaching, improve the teaching quality of personnel training, accurate positioning, reasonable construction of talent training system, how will the photoelectric information has very important significance to students to become a qualified professional talents.

\section{PROBLEMS IN TALENT TRAINING}

\subsection{Emphasizing theory and neglecting practice}

Teaching, emphasis on theoretical teaching, neglect of the practice of teaching. Most of students are in the classroom to learn theoretical knowledge, due to the difficulty of professional courses, resulting in students to understand the professional theoretical knowledge is not thorough enough. Although the professional courses are still the corresponding content of practical teaching, but the content of more practical teaching practice, design and comprehensive practice teaching content is relatively small. Students are usually in accordance with the guidance of teachers step by step to do, the lack of independent analysis of problems and problem-solving ability, practical application of poor. Although the Institute of Electronic Information Science and Technology for the national comprehensive reform pilot project and the Hubei Provincial College of strategic (emerging) pillar industry undergraduate talent training project undergraduate, photoelectric information science and engineering for the Hubei provincial higher school strategic (new) pillar Industrial talent cultivation program undergraduate programs and Hubei comprehensive reform pilot professional. But the depth of school-enterprise cooperation is not enough, is still in accordance with the traditional disciplines system of teaching content, students practice less, the application of capacity development cannot be effectively developed.

\subsection{Lack of "dual capacity" teachers}

At present, our hospital has 48 professional teachers, 44 teachers after graduation into the work of colleges and universities, there is no work experience, the enterprise project implementation know little about the lack of practical experience in the application. 4 teachers have business background, there are four teachers participated in the "Hubei Provincial Higher School Young Teachers in-depth enterprise action plan project." Although they are in the enterprise after the job training to get a certain experience in engineering applications, but these experiences are one-sided, partial, not long-term accumulation and systematic. Therefore, the lack of engineering ability of teachers themselves restricts the students' ability of engineering practice, innovation and entrepreneurship development.

\section{THE COUNTERMEASURE IN THE PROCESS OF PERSONNEL TRAINING}

\subsection{Talent training program "application"}

Application-oriented personnel training program should be an open dynamic structure system which takes industrial development as the orientation and can reflect the development trend of the industry and reflects the practicality and application demand of the industry and leads the industry development. Since 2015, our hospital began to electronic information engineering, electronic information science and technology, optoelectronic information science and engineering, light and lighting and electrical engineering and automation five undergraduate professional implementation photoelectric information class enrollment, the 2013 version of the talent the training program was revised. The newly revised talent training program is to scientifically define the training objectives and personnel training standards of the professional talents, and carefully select the mode of personnel training, and rationally construct the four modules of general education curriculum, basic course, core curriculum and professional direction. Program and guided study program, reflects the application of talent training mode of the core position.

\subsection{Teachers "application"}

It is important to improve the teaching level of the existing teaching staff and increase the application background of teachers. In particular, through the close cooperation with the enterprises, the theory curriculum teachers and the practice teachers are formed. The application of the teaching staff is the key point. And corporate part-time teachers diversified teaching team. Specific measures are as follows: First, the cultivation and introduction of outstanding academic leaders, the creation of teaching and academic team, with the innovative quality of the outstanding teachers to provide conditions for the team; the second is for key teachers, especially young teachers, to increase its research and Teaching support, encourage teachers to practice enterprise training, improve master production design and product development capabilities; third is to hire outstanding entrepreneurs and senior engineering and technical personnel for the college part- 
time teachers, joint construction of professional courses, the gradual implementation of internships Training "double guidance" system, graduation design (thesis) "dual mentor" system, targeted training students practical awareness and social responsibility.
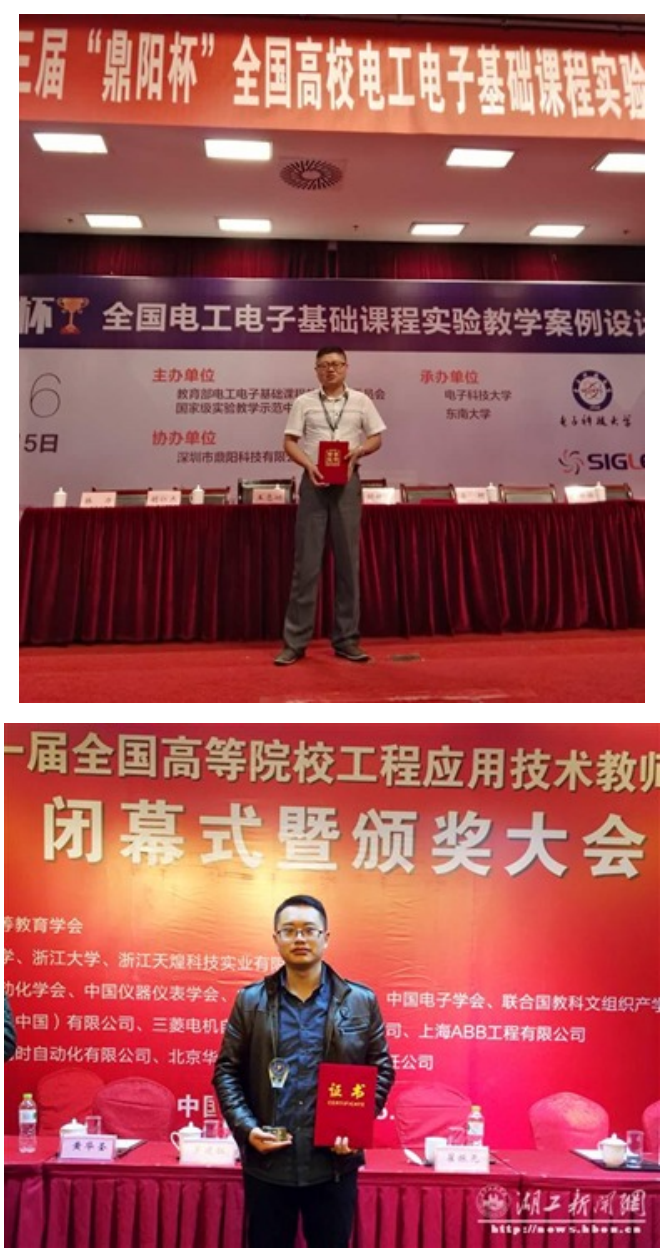

Figure 1. Teachers have been awarded prizes in the process of the applied skill competitions

\subsection{Teaching content "application"}

Teaching content "application" is based on the cultivation of applied talents in the teaching reform focus needs in accordance with the application of talent growth needs knowledge structure to reform the teaching content. On the one hand is to optimize the knowledge structure. By optimizing the knowledge structure, teachers are encouraged to carry out reform and research of teaching content, so as to promote the updating of teaching content, so as to keep the teaching content as advanced and advanced as possible, including the advanced concepts, Thus highlighting the explicit knowledge and tacit knowledge double; on the other hand relying on innovative practice platform. Such as the use of the central government to support the development of local colleges and universities to build a special fund of information technology control engineering teaching experimental platform, reasonable, natural and accurate into the application of teaching content, active classroom atmosphere, triggering positive thinking and exploration of students, thus promoting Cultivation of Applied Talents. 


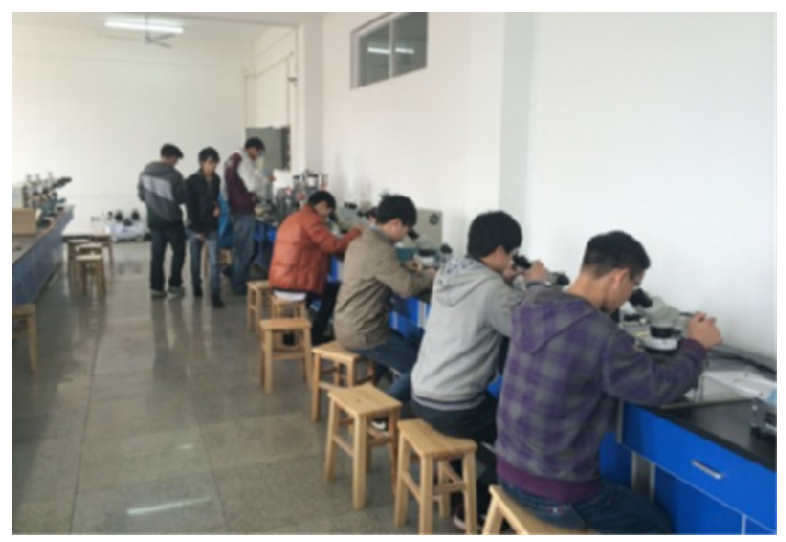

Figure 2. Students have accepted the experimental course training

\subsection{Practical teaching "application "}

Practical teaching is to cultivate students' practical ability and comprehensive quality of teaching methods, is the cultivation of high-quality application-oriented talents important way. Through the establishment of practical teaching platform, promote practical teaching "application". The practical teaching platform consists of the experimental teaching center which provides the open teaching resources, the open operation mechanism and the training program. Reform practice teaching content, improve practice teaching condition, innovate practice teaching mode, increase comprehensive and design experiment, and advocate self-selection and cooperative experiment. Through the open laboratory, innovation center and internship training base, actively organize students to participate in the national college students "Challenge Cup", electronic design competition and optoelectronic design competition and other professional background of the competition, and actively encourage students to participate in professional-related professional qualifications Certificate examination, so as to cultivate students' ability to combine theory with practice and innovation ability, and to improve the quality of applied talents training.

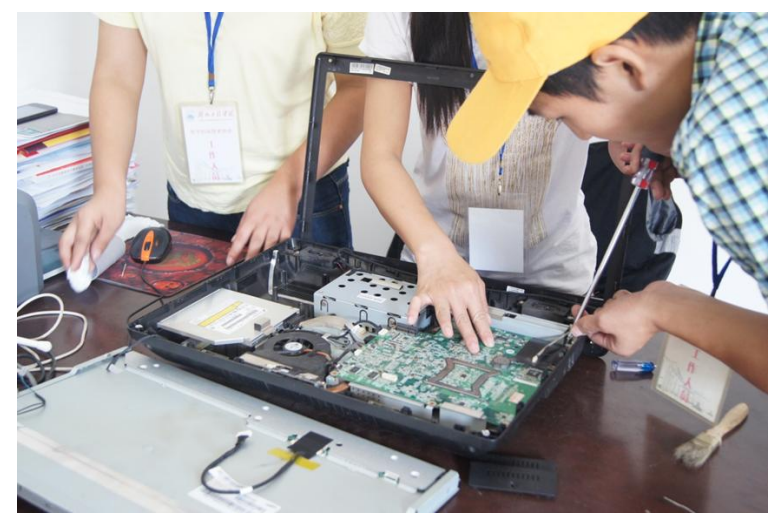

Figure 3. Students have applied talents training

\subsection{Research and promote "application"}

Research and teaching is to closely focus on training students' application-oriented thinking and improve the application of the ability of students to carry out research. First, to encourage teachers to carry out professional and related research work and application-oriented research to improve the application of the ability of teachers and teaching level; the second is to encourage students to participate in various practical activities. And actively organize students to participate in electronic design competition and targeted to carry out student science and technology activities to increase students' independent learning and practice opportunities, can effectively promote students to professional learning; third is to encourage students to participate in teacher research activities. Mainly in the graduation project (thesis) link, arrange and encourage students to participate in teacher research, truly "Zhenti do", the research part of the content as a student graduation design practice teaching content. This process not only enables students to apply the practical ability to get a comprehensive exercise and improve, and can significantly improve the quality of graduation design. 


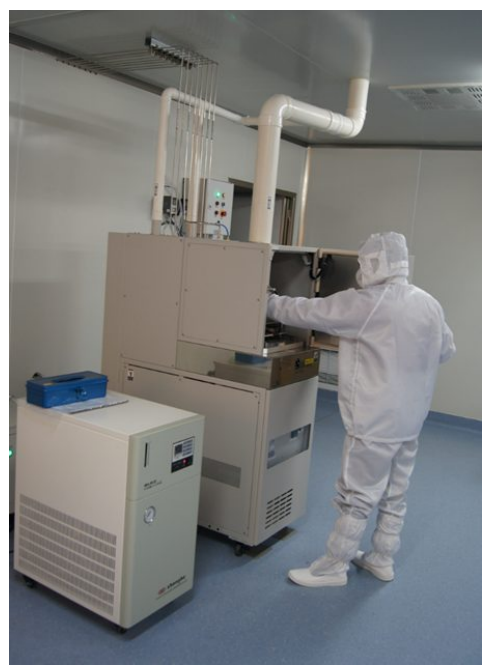

Figure 4. Students have accpeted talents training in scientific research

\section{CONCLUSIONS}

Photoelectric information specialty training path of applied talents, we need in theory and practice two levels, actively explore, strengthen research and innovation, and in the continuous development of practice to be summed up and improved, which will be conducive to the photoelectric Information-based professional construction to become close to the development of enterprises and enterprises, the depth of integration of school and enterprise training regional economic services of high-end electronic information technology talent base, to improve the quality of local economic construction and development of talent is important.

\section{ACKNOWLEDGMENTS}

This research was supported by the Research Foundation of Education Bureau of Hubei Province (Grant No. 2014378, 2016398), and Hubei Engineering University (Grant No.2014A26)

\section{REFERENCES}

[1]. Wang Z, Pi J, Ba Z, "Thoughts on cultivating application-oriented talents majoring in materials science and engineering," Journal of Nanjing Institute of Technology (Social Science Edition), 1: 010(2007).

[2]. Cui G, Jia Y, "Reform \& practice for training of Application-oriented talents of automation," research and exploration in laboratory, 11:035(2009).

[3]. Tan F, Luo C, Wang L, "Research on cultivating patterns of application-oriented talents of engineering: a case study of Shandong Jianzhu University," Journal of Shandong Jianzhu University, 1: 034(2012).

[4]. Zhang Y, Ma J, Wang X, "Improving the training quality of application-oriented talents by enhancing the construction of experiment center," Research and Exploration in Laboratory, 11: 028(2011).

[5]. Ding D L, "College art education viewed in the light of the outline of china's national plan for medium and longterm education reform and development," Journal of Aesthetic Education, 90(4):21-48(2010).

[6]. Sun X B, "The national medium- and long-term educational reform and development guideline (2010-20)," Chinese Education \& Society, 45(3):9-22(2012). 
[7]. Sierra J F G, Martínez N F, Prieto A M S, et al, "Interdisciplinary collaboration in the practical teaching of pharmacology: use of experimental animals and applied robotics," Basic \& Clinical Pharmacology \& Toxicology, 117: 15-16(2015).

[8]. Huang Z F, Wei Y Q, "The current situation in curriculum settings of physical education major and its futureconceptions in new undergraduate colleges and universities - taking new undergraduate colleges and universities in guangxi province of china as an example," Proc. MIEE, 641-644(2014).

[9]. Honig M I, Rainey L R, "Central office leadership in principal professional learning communities: The practice beneath the policy," Teachers College Record, 116(4): 1-48(2014).

[10]. Tseng F C, Kuo F Y, "A study of social participation and knowledge sharing in the teachers' online professional community of practice," Computers \& Education, 72: 37-47(2014). 